\title{
Magnetic Resonance-Guided Radiotherapy
}

National Cancer Institute

\section{Source}

National Cancer Institute. Magnetic Resonance-Guided Radiotherapy. NCI Thesaurus.

Code C150808.

A therapeutic procedure that utilizes magnetic resonance imaging for detailed anatomic visualization immediately before or during radiation treatment. 